\title{
Exploring the Use of Twitter by Leading Medical Centers in the United States
}

\author{
Nima Kordzadeh \\ Worcester Polytechnic Institute \\ nkordzadeh@wpi.edu
}

\begin{abstract}
Healthcare organizations such as hospitals and clinics increasingly use social media platforms such as Twitter to raise awareness in the community about health and wellness issues. In line with this trend, the current study seeks to understand how Cleveland Clinic, Johns Hopkins Hospital, and Mayo Clinic use their primary Twitter accounts to post information related to each of the following major health topics: brain, cancer, diabetes, diet, exercise, heart, mental health, and obesity. Nearly 6,000 tweets posted by those medical centers were collected and analyzed. The results showed that the three medical centers used diet and cancer topics more frequently than the other six topics in their tweets. Moreover, diabetes was consistently the least frequently used topic in the analyzed tweets. The results associated with the other five topics were mixed.
\end{abstract}

\section{Introduction}

Twitter has become a major social media channel through which organizations in different industries communicate with their audiences [3]. In the healthcare sector, hospitals, clinics, and other medical organizations use Twitter, as well as, other social media platforms to educate people on health and wellness topics, promote healthcare services and products, and strengthen ties with patients and the surrounding community [7-9, 11, 17, 18]. For example, the results of a study in 2014 showed that more than 50\% (1713/3371) of the sampled hospitals had Twitter accounts. Some hospitals' twitter channels have a few hundred followers (e.g., Kapiolani Medical Center for Women \& Children located in Honolulu, Hawaii), whereas other hospitals have hundreds of thousands of followers on Twitter (e.g., Cleveland Clinic located in Cleveland, Ohio).

Healthcare organizations that use Twitter, or are planning to embrace this platform, need to first formulate a social media strategy, decide on what content to post on their channels, and learn how to effectively use Twitter, among other social media environments, to promote health and wellness in the community. To do so, those organizations can learn from healthcare providers that have successfully adopted social media technologies. Cleveland Clinic, Mayo Clinic, and Johns Hopkins Hospital are three major medical centers in the United States that have pioneered the use of social media in healthcare [7, 12]. They have been consistently active in educating people and raising awareness about diseases, health conditions, medications, and other health and wellness topics through social media channels. Table 1 presents these organizations' account information and activities on Twitter as of May 2018. Accordingly, they have collectively posted more than 100 thousand tweets and currently have more than four million followers on Twitter. Therefore, these three organizations are playing a major role in leveraging social media, in particular Twitter, to promote health and wellness in the community.

Table 1: The three medical centers' Twitter account information

\begin{tabular}{|l|l|l|l|l|}
\hline Medical Center & Username & $\begin{array}{l}\text { Year of joining } \\
\text { Twitter }\end{array}$ & Number of Tweets & Number of followers \\
\hline Cleveland Clinic & @ClevelandClinic & 2009 & 44.4 thousand & 1.830 million \\
\hline Johns Hopkins Hospital & @HopkinsMedicine & 2009 & 18.7 thousand & 0.513 million \\
\hline Mayo Clinic & @MayoClinic & 2008 & 41.2 thousand & 1.910 million \\
\hline
\end{tabular}


Cleveland Clinic, Mayo Clinics, and Johns Hopkins Hospital have also been consistently ranked among the top hospitals in the United States in terms of quality of care they provide to their patients as well as their approach in integrating clinical and healthcare services with research and education. According to the most recent hospital ranking published by U.S. News \& World Report (2017-2018), these three hospitals have been ranked as the top medical centers in the nation for services such as diabetes and endocrinology, nephrology, urology, and gastroenterology [13]. Therefore, these renowned hospitals and their Twitter activities can be used as a benchmark by other healthcare organizations that are starting to embark on social media strategies or are planning to expand and improve their activities on Twitter. This study takes a major step along this path by analyzing the content of tweets made by these three organizations.

Prior research has investigated the health topics that are generally discussed on Twitter [10] or are focused on by health organizations such as American Heart Association and American Diabetes Association [14]. Nonetheless, very few studies have specifically analyzed tweets made by hospitals and clinics in the United States to understand the health topics they use more frequently in their tweets. The current study addresses this gap in the literature and aims to create a benchmark for other healthcare organizations. We specifically focus on eight popular health topics including diabetes, diet, exercise, obesity, mental health, cancer, heart, and brain issues. We chose these eight topics based on the results of prior research that have collectively shown that these topics are among the major health issues (e.g., cancer and diabetes) and preventive measures of diseases (e.g., exercise and diet) in the United States that are popular, interesting, and important to Twitter users [2, 10, 14, 16]. Accordingly, we seek to address the following research question (RQ):

RQ1: How do major medical centers in the United States use Twitter to disseminate information about popular health-related topics?

\section{Literature review}

Prior studies have shown that healthcare institutions are increasingly using social media websites such as Facebook and Twitter to promote healthy lifestyle and share health-related information with a broader community of health consumers. A study of 11 medical institutions in Central Pennsylvania revealed that disease or condition awareness was among the commonly used themes in those institutions' Facebook posts [6]. The results of a similar, but more recent and comprehensive study demonstrated that sharing health information such as those related to health issues, medications, treatments, and diet, was the most frequently used theme in the posts made by 17 hospitals on Facebook [12]. The authors reported that sharing health information appeared in more than 35\% (424/1184) of the posts, whereas the second most frequently used theme, namely recognizing employees, was used in only $15 \%$ (177/1184) of the posts. Kordzadeh and Young [12], however, did not explore specific diseases and health topics to understand which topics were used more commonly than the others.

In the context of Twitter, Diddi and Lundy [4] analyzed 2,916 tweets made by four healthcare institutions, including a Women's Hospital, to understand how those institutions used their Twitter accounts to raise awareness about breast cancer. The authors found that around $41 \%$ of the breast cancerrelated tweets made by the Women's Hospital were related to the perceived threats associated with that type of cancer. In addition, nearly $27 \%$ of the tweets focused on the benefits of different breast cancer treatments. In a similar study, Chung [2] analyzed around 1,000 tweets related to breast cancer and found that the tweets were posted mainly for promotional goals of fundraising or sales events and fewer tweets were used for educational purposes or raising awareness about breast cancer.

Other researchers have focused on other types of health-related organizations. Park, Reber [14] analyzed nearly 1,600 tweets published by the American Heart Association, American Cancer Society, and American Diabetes Association. The results of that study revealed that the majority of tweets were related to organizational topics, whereas personal health-related tweets constituted a smaller portion of the sample. The authors categorized the health-related tweets based on their topics into two groups: personal health information and personal health action. The themes under personal health information were: 1) reporting medical research on diseases, 2) delivering general health information, 3) information people about health risks, and 4) addressing social or political issues such as health policies and healthcare systems. The themes under personal health action included 1) encouraging people to receive preventive health screening, 2) encouraging people to modify their lifestyle or maintain their health behavior, and 3) soliciting people to take action to learn more and increase knowledge. The results of that thematic analysis, however, did not show what types of diseases and medical conditions were more often included in the analyzed tweets.

In summary, prior studies have not paid adequate attention to the different topics that hospitals and 
clinics post on their Twitter pages. Instead, those studies either have focused on other platforms such as Facebook [6, 12] or other types of healthcare institutions such as health-related government agencies $[14,15]$, or have investigated only one or two health-related topics such as breast cancer [2, 4]. The present study extends the extant literature by examining eight popular health topics and three major medical centers' Twitter accounts.

\section{Method}

A keyword-based, thematic analysis was employed in this study. Thematic analysis is generally, a qualitative research method used to identify themes and analyze their frequency and pattern of use in text data [1]. Thematic analysis can be employed deductively or inductively [5]. When used deductively, an existing theory, model, or framework dictates the set of themes that are searched for in the data. Inductive use is more exploratory as themes are allowed to emerge from the data during the analysis process [5]. The present study employs a deductive thematic analysis because the intention is not to develop a comprehensive thematic web of content including all the themes and purpose groups used in the tweets; rather, the focus is on understanding how the three leading medical centers disseminate information related to a set of eight popular topics in their tweets.

We collected nearly 6,000 tweets posted on Twitter by Cleveland Clinic, Johns Hopkins Hospitals, and Cleveland Clinic during the six-month period from May 2017 to November 2017. We only looked at the primary Twitter accounts affiliated with those medical centers. We then created a basket of keywords for each of the eight health topics. The keywords were adapted from the extant literature or medical dictionaries. Through a preliminary exploration of the tweets, we noticed that the three medical centers did not use highly advanced medical terms in their tweets, most likely to let people with little medical knowledge understand what they meant by each tweet. Accordingly, we did not include advanced medical terms related to each topic in the basket of keywords.

Next, we coded each tweet using a combination of eight dummy variables representing the eight topics. Each tweet would get a " 1 " for each topic if at least one of the keywords associated with that topic was present in the tweet. Otherwise, the tweet would get a " 0 " for that topic. Then, we manually checked all the tweets and made adjustments to their coding wherever needed. For example, "run” was one of the keywords under the exercise topic, whereas there were some tweets that contained the phrase "running late" and hence, were initially coded as exercise-related tweets (because of the presence of the term "run" in the tweet). However, the contextual meaning of "run" in those tweets was not semantically consistent with the exercise topic. Therefore, we manually recoded those tweets. Through the manual recoding process, whenever we found additional keywords related to each topic that we had not initially included in the basket of keywords, we added them to the list of keywords and re-ran the coding queries in Excel. This iterative keyword detection process helped us improve the reliability of the entire coding process. Figure 1 presents two sample tweets. Table 2 presents a sample of keywords and tweets used in this study.

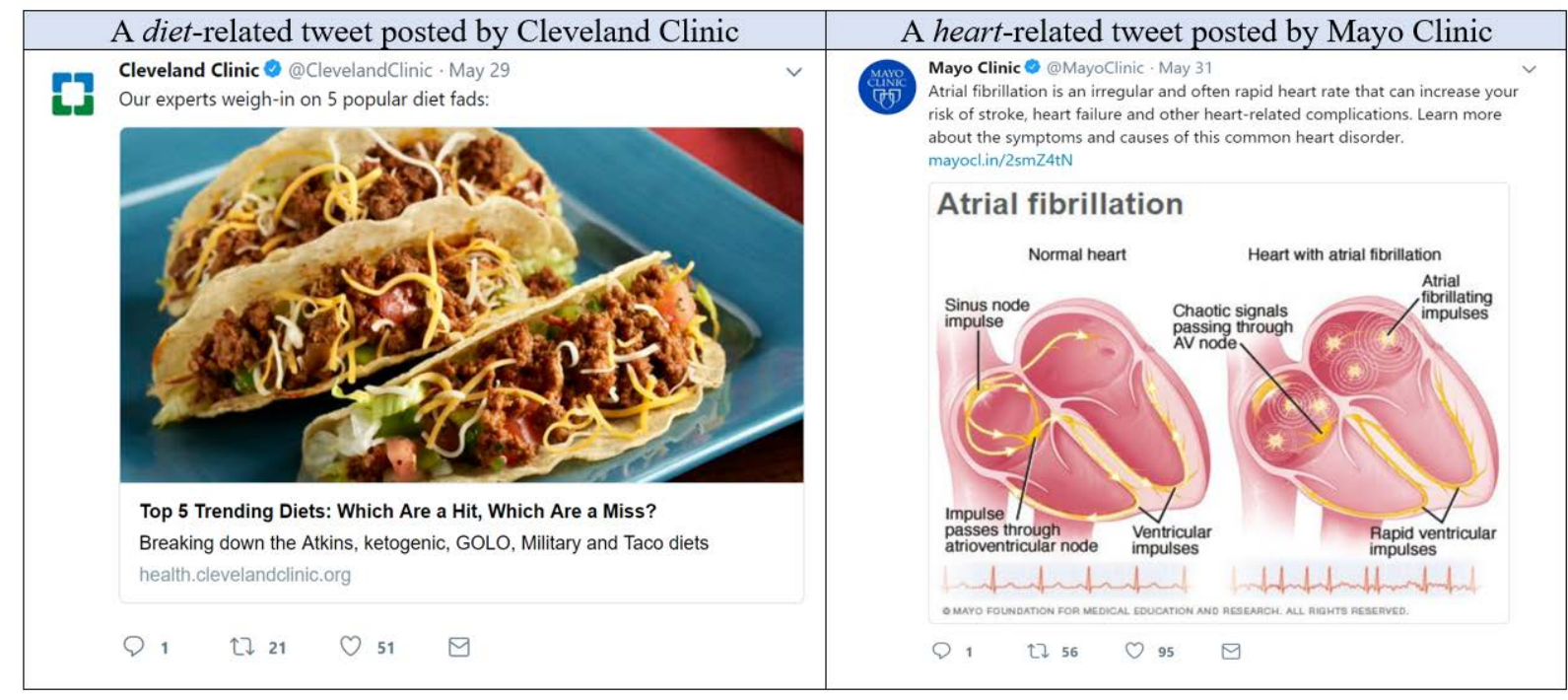

Figure 1: Two sample tweets 
Table 2: Sample keywords and tweets for each topic

\begin{tabular}{|c|c|c|c|}
\hline Topic & Sample keywords & Medical center & Sample tweets \\
\hline \multirow[t]{3}{*}{ Brain } & \multirow{3}{*}{$\begin{array}{l}\text { brain, memory, } \\
\text { stroke, migraine, } \\
\text { headache, dizzy } \\
\text { dizziness, } \\
\text { Alzheimer's }\end{array}$} & $\begin{array}{l}\text { Cleveland } \\
\text { Clinic }\end{array}$ & 12 facts about your \#brain that will blow your mind! \\
\hline & & $\begin{array}{l}\text { Johns Hopkins } \\
\text { Hospital }\end{array}$ & $\begin{array}{l}\text { Follow these } 4 \text { daily habits a Johns Hopkins memory disorder } \\
\text { expert says could protect your \#brain health. }\end{array}$ \\
\hline & & Mayo Clinic & $\begin{array}{l}1 \text { in } 50 \text { people have an unruptured brain aneurysm, and many } \\
\text { don't even know it. }\end{array}$ \\
\hline \multirow[t]{3}{*}{ Cancer } & \multirow{3}{*}{$\begin{array}{l}\text { cancer, chemo, } \\
\text { tumor, oncology, } \\
\text { oncologist }\end{array}$} & $\begin{array}{l}\text { Cleveland } \\
\text { Clinic }\end{array}$ & $\begin{array}{l}\text { Don't ignore these } 5 \text { vague signs of cervical and ovarian } \\
\text { cancer. }\end{array}$ \\
\hline & & $\begin{array}{l}\text { Johns Hopkins } \\
\text { Hospital }\end{array}$ & $\begin{array}{l}\text { Did you know that colon cancer is the second leading cause of } \\
\text { cancer death in the United States today? }\end{array}$ \\
\hline & & Mayo Clinic & $\begin{array}{l}\text { \#Cancer researchers are working on vaccines aimed at } \\
\text { keeping cancer cells from spreading. }\end{array}$ \\
\hline \multirow[t]{3}{*}{ Diabetes } & \multirow{3}{*}{$\begin{array}{l}\text { diabetes, glucose, } \\
\text { blood sugar, } \\
\text { insulin }\end{array}$} & $\begin{array}{l}\text { Cleveland } \\
\text { Clinic }\end{array}$ & BEST and WORST \#diet choices if you have \#diabetes \\
\hline & & $\begin{array}{l}\text { Johns Hopkins } \\
\text { Hospital }\end{array}$ & $\begin{array}{l}\text { Can a new pill developed at Johns Hopkins effectively stop } \\
\text { \#diabetes symptoms? }\end{array}$ \\
\hline & & Mayo Clinic & \#Researchers link \#Alzheimer's gene to Type 3 \#diabetes. \\
\hline \multirow[t]{3}{*}{ Diet } & \multirow{3}{*}{$\begin{array}{l}\text { food, diet, eat, } \\
\text { cook, fasting, } \\
\text { nutrients, carbs, } \\
\text { recipe, lunch, } \\
\text { fruit, delicious }\end{array}$} & $\begin{array}{l}\text { Cleveland } \\
\text { Clinic }\end{array}$ & What are the benefits of TURMERIC and how do you take it? \\
\hline & & $\begin{array}{l}\text { Johns Hopkins } \\
\text { Hospital }\end{array}$ & Myth: You should switch to a low-carb, high-protein diet. \\
\hline & & Mayo Clinic & \#MayoClinicRecipes: Roasted butternut squash risotto \\
\hline \multirow[t]{3}{*}{ Exercise } & \multirow{3}{*}{$\begin{array}{l}\text { workout, run, } \\
\text { fitness, gym, } \\
\text { bodybuilding, } \\
\text { treadmill, swim, } \\
\text { walk, physical } \\
\text { activity, climb }\end{array}$} & $\begin{array}{l}\text { Cleveland } \\
\text { Clinic }\end{array}$ & $\begin{array}{l}\text { Can't shake the soreness after a workout? Your diet may be a } \\
\text { solution: }\end{array}$ \\
\hline & & $\begin{array}{l}\text { Johns Hopkins } \\
\text { Hospital }\end{array}$ & $\begin{array}{l}8 \text { Questions Answered About \#Exercise That You May Not } \\
\text { Know: }\end{array}$ \\
\hline & & Mayo Clinic & $\begin{array}{l}\text { Love \#exercise? Turns out, too much of it may actually put } \\
\text { your heart at risk. }\end{array}$ \\
\hline \multirow[t]{3}{*}{ Heart } & \multirow{3}{*}{$\begin{array}{l}\text { heart, aorta, } \\
\text { arterial, mitral, } \\
\text { cardio, cardiac }\end{array}$} & $\begin{array}{l}\text { Cleveland } \\
\text { Clinic }\end{array}$ & Seven habits to kick if you want a healthier \#heart: \\
\hline & & $\begin{array}{l}\text { Johns Hopkins } \\
\text { Hospital }\end{array}$ & $\begin{array}{l}\text { This week on \#PodMed: Can eating chocolate keep the } \\
\text { cardiologist away? }\end{array}$ \\
\hline & & Mayo Clinic & Women with NAFLD at higher risk of \#HeartDisease. \\
\hline \multirow[t]{3}{*}{$\begin{array}{l}\text { Mental } \\
\text { Health }\end{array}$} & \multirow{3}{*}{$\begin{array}{l}\text { Mental, stress, } \\
\text { depression, } \\
\text { anxiety, bipolar, } \\
\text { autism, ADHD, } \\
\text { schizophrenia, } \\
\text { negative thought }\end{array}$} & $\begin{array}{l}\text { Cleveland } \\
\text { Clinic }\end{array}$ & $\begin{array}{l}\text { Annual screenings could prevent \#depression in people with } \\
\text { type } 2 \text { \#diabetes. }\end{array}$ \\
\hline & & $\begin{array}{l}\text { Johns Hopkins } \\
\text { Hospital }\end{array}$ & $\begin{array}{l}\text { How does ADHD affect teenage driving? Hear the answer to } \\
\text { this question and others on PodMed this week: }\end{array}$ \\
\hline & & Mayo Clinic & $\begin{array}{l}\text { Don't let the stigma of \#mentalillness stand in the way of } \\
\text { getting treatment. }\end{array}$ \\
\hline \multirow[t]{3}{*}{ Obesity } & \multirow{3}{*}{$\begin{array}{l}\text { obesity, obese, } \\
\text { fat, weight loss, } \\
\text { waistline, fit, } \\
\text { weight gain }\end{array}$} & $\begin{array}{l}\text { Cleveland } \\
\text { Clinic }\end{array}$ & $\begin{array}{l}\text { Why it's harder to lose weight after } 40 \text { (and tips to keep you } \\
\text { trim): }\end{array}$ \\
\hline & & $\begin{array}{l}\text { Johns Hopkins } \\
\text { Hospital }\end{array}$ & Does Sugar Contribute to Weight Gain? \\
\hline & & Mayo Clinic & Portion control is key for \#weightloss. \\
\hline
\end{tabular}




\section{Data analysis and results}

The results, presented in Table 3, showed that all the three medical centers used diet and cancer topics more frequently than the other six themes in their tweets such that those two topics together represented about $29 \%$, 26\%, and $24 \%$ of the entire tweets made by Cleveland Clinic, Johns Hopkins Hospital, and Mayo Clinic, respectively. More specifically,
Cleveland Clinic used diet and cancer topics in $23.61 \%$ and $5.20 \%$ of their tweets, respectively. This finding implies that they mainly used Twitter to share diet-related information with society. The percentages of the other two medical centers' tweets that contained diet and cancer keywords, however, were more evenly distributed (i.e., $11.30 \%$ and $14.41 \%$ for Johns Hopkins and $11.13 \%$ and $12.29 \%$ for Mayo Clinic, respectively).

Table 3: Frequency distribution of topics for each medical center

\begin{tabular}{|l|l|l|l|l|l|l|l|l|l|}
\hline Hospital & $\begin{array}{l}\text { Total \# } \\
\text { of tweets }\end{array}$ & Brain & Cancer & Diabetes & Diet & Exercise & Heart & $\begin{array}{l}\text { Mental } \\
\text { Health }\end{array}$ & Obesity \\
\hline $\begin{array}{l}\text { Cleveland } \\
\text { Clinic }\end{array}$ & 2960 & $\begin{array}{l}110 \\
(3.72 \%)\end{array}$ & $\begin{array}{l}154 \\
(5.20 \%)\end{array}$ & $\begin{array}{l}17 \\
(0.57 \%)\end{array}$ & $\begin{array}{l}699 \\
(23.61 \%)\end{array}$ & $\begin{array}{l}74 \\
(2.50 \%)\end{array}$ & $\begin{array}{l}117 \\
(3.95 \%)\end{array}$ & $\begin{array}{l}101 \\
(3.41 \%)\end{array}$ & $\begin{array}{l}133 \\
(4.49 \%)\end{array}$ \\
\hline $\begin{array}{l}\text { Johns } \\
\text { Hopkins } \\
\text { Hospital }\end{array}$ & 708 & $\begin{array}{l}57 \\
(8.05 \%)\end{array}$ & $\begin{array}{l}102 \\
(14.41 \%)\end{array}$ & $\begin{array}{l}6 \\
(0.85 \%)\end{array}$ & $\begin{array}{l}80 \\
(11.30 \%)\end{array}$ & $\begin{array}{l}24 \\
(3.39 \%)\end{array}$ & $\begin{array}{l}65 \\
(9.18 \%)\end{array}$ & $\begin{array}{l}35 \\
(4.94 \%)\end{array}$ & $\begin{array}{l}25 \\
(3.53 \%)\end{array}$ \\
\hline $\begin{array}{l}\text { Mayo } \\
\text { Clinic }\end{array}$ & 2327 & $\begin{array}{l}175 \\
(7.52 \%)\end{array}$ & $\begin{array}{l}286 \\
(12.29 \%)\end{array}$ & $\begin{array}{l}18 \\
(0.77 \%)\end{array}$ & $\begin{array}{l}259 \\
(11.13 \%)\end{array}$ & $\begin{array}{l}181 \\
(7.78 \%)\end{array}$ & $\begin{array}{l}99 \\
(4.25 \%)\end{array}$ & $\begin{array}{l}60 \\
(2.58 \%)\end{array}$ & $\begin{array}{l}41 \\
(1.76 \%)\end{array}$ \\
\hline Total & 5995 & $\begin{array}{l}342 \\
(5.70 \%)\end{array}$ & $\begin{array}{l}542 \\
(9.04 \%)\end{array}$ & $\begin{array}{l}41 \\
(0.68 \%)\end{array}$ & $\begin{array}{l}1038 \\
(17.31 \%)\end{array}$ & $\begin{array}{l}279 \\
(4.65 \%)\end{array}$ & $\begin{array}{l}281 \\
(4.69 \%)\end{array}$ & $\begin{array}{l}196 \\
(3.27 \%)\end{array}$ & $\begin{array}{l}199 \\
(3.32 \%)\end{array}$ \\
\hline
\end{tabular}

A difference between Mayo Clinics and the other two medical centers in terms of topic distribution was that Mayo Clinic used exercise topics in nearly $7.78 \%$ of their tweets, whereas Cleveland Clinic and Johns Hopkins hospital used only $2.50 \%$ and $3.39 \%$ of their tweets, respectively, to share exercise-related tips and advice. Accordingly, Mayo Clinic focused on exercise topics on Twitter more than the other two medical centers. Moreover, Mayo Clinic used Twitter to promote its mobile app, which could be used by health consumers to receive fitness and health behavior tips on a regular basis. For instance, one of the tweets that Mayo Clinic has made to promote its mobile app is as follows:

"Walk with resistance to build stronger hips and protect your knees. For \#fitness tips, download the Mayo Clinic app.”

Using this tweet and similar ones, Mayo Clinic has tried to not only share a fitness tip, but also encourage people to download, install, and use the app. Interestingly, despite the high proportion of the Mayo Clinic's tweets devoted to fitness and exercise topics, very low percentage of their tweets $(1.76 \%)$ were related to obesity.

The three medical centers were also different in terms of the use of heart and brain topics and keywords in their tweets. 9.18\% and 8.05\% of Johns Hopkins' tweets focused on heart and brain topics, whereas those numbers for Cleveland Clinic were less than $4 \%$ and for Mayo Clinic were $4.25 \%$ and $7.52 \%$, respectively. This means that Johns Hopkins' concentration on those two topics was relatively higher than the other two hospitals, especially Mayo Clinic. Mental health was another topic that Johns Hopkins tweeted about more than the other two medical centers did. Nearly 5\% of Johns Hopkins' tweets were related to mental health, whereas that number for Mayo Clinic and Cleveland Clinic were $2.58 \%$ and $3.41 \%$, respectively.

On the similarities between the three medical centers' tweeting activities, diabetes was consistently the least commonly used topic in the tweets. All the three medical centers used diabetes keywords in less than $1 \%$ of their tweets. This finding is in contrast to Karami et al.'s (2017) findings that showed diabetes was one of the most widely discussed topics on Twitter.

\section{Discussion}

The results of analyzing nearly 6,000 tweets made by three major medical centers showed that there were similarities and differences between those institutions in terms of the topics that they incorporated into their tweets. For instance, diet was consistently among the most frequently used topics in the sampled tweets, whereas diabetes was by far the least frequently used topic. Each of the three healthcare institutions, 
however, had a distinct approach in tweeting about different topics. Cleveland Clinic, for example, mainly focused on diet topics. Mayo Clinic distributed its tweets more evenly across four topics including diet, exercise, cancer, and brain. Finally, Johns Hopkins directed its attention toward diet, cancer, heart, and brain topics.

A practical implication of our results is that although there is no single correct approach that healthcare institutions should take when using Twitter to disseminate health information, there are some general guidelines that they can follow. For example, diet, exercise, and cancer are the three major themes that the medical centers under investigation in this study mainly focused on in their tweets. Given that these three institutions are known for providing high quality healthcare services, they are expected to be aware of the topics that are important and useful to the population of the United States. Thus, a hospital or clinic that is planning to start using Twitter can start posting tweets related to these specific topics to address some informational needs of society. Nonetheless, a specialty clinic that, for example, only provides neurosurgery services, may not follow the general tweeting guidelines and can (or should) specifically focus on the topics related to neurosurgery. Our findings also added to the literature on health communication, education, and promotion using social media platforms.

A limitation of this study is that we collected data from only three healthcare institutions' primary Twitter channels. Future research can extend our results by collecting and analyzing more tweets from a wider range of healthcare organizations' Twitter accounts to better understand how different types of clinics and hospitals (in terms of rural vs urban, educational vs non-educational, general care vs. specialty care, etc.) follow different directions in the topics they focus on in Twitter. Another limitation of this study is that we did not inductively analyze the tweets to find all the topics and subtopics contained in them. Rather, we considered the eight health-related topics and used only a set of keywords related to those topics in our analysis. Future research can perform a more comprehensive thematic analysis to understand the major and minor themes of health-related topics that are present in tweets made by healthcare institutions. Moreover, researchers in future studies can examine user engagement in terms of number of likes, retweets, and shares with regard to each theme of content. The results of such studies can potentially help healthcare organizations realize what topics are more interesting to people and to what extent each theme of content can draw followers' attention and trigger reactions and interactions on Twitter.

\section{Conclusion}

Twitter has become a mass communication platform for healthcare institutions. Thus, it is critical for them to make effective decisions related to which topics they should focus on in their tweets and how frequently they should make posts related to each topic. Our results showed that Cleveland Clinic, Johns Hopkins Hospital, and Mayo Clinic followed different tweeting approaches. Hence, other healthcare institutions in the United States can adjust their tweeting activities if they want to follow any of the three pioneers of social media use in the context of healthcare.

\section{References}

[1] V. Braun and V. Clarke. 2006. "Using thematic analysis in psychology". Qualitative Research in Psychology, 3(2), pp. 77-101.

[2] J.E. Chung. 2017. "Retweeting in health promotion: Analysis of tweets about Breast Cancer Awareness Month". Computers in Human Behavior, 74, pp. 112-119.

[3] M.J. Culnan, P.J. McHugh, and J.I. Zubillaga. 2010. "How large US companies can use Twitter and other social media to gain business value". MIS Quarterly Executive, 9(4).

[4] P. Diddi and L.K. Lundy. 2017. "Organizational Twitter Use: Content Analysis of Tweets during Breast Cancer Awareness Month". Journal of Health Communication, 22(3), pp. 243-253.

[5] J. Fereday and E. Muir-Cochrane. 2006. "Demonstrating rigor using thematic analysis: A hybrid approach of inductive and deductive coding and theme development". International Journal of Qualitative Methods, 5(1), pp. 8092.

[6] D.R. George, L. Kime, and T.D. Riley. 2015. "How are healthcare institutions using Facebook to interact with online communities? Results from a case study in Central Pennsylvania". Journal of Hospital Administration, 4(3), pp. 89.

[7] C. Gomes and A. Coustasse. 2015. "Tweeting and treating: how hospitals use twitter to improve care". The Health Care Manager, 34(3), pp. 203-214.

[8] H.M. Griffis, A.S. Kilaru, R.M. Werner, D.A. Asch, J.C. Hershey, S. Hill, . . . R.M. Merchant. 2014. "Use of social media across US hospitals: descriptive analysis of adoption and utilization". Journal of Medical Internet Research, 16(11). 
[9] C. Hawn. 2009. "Take two aspirin and tweet me in the morning: how Twitter, Facebook, and other social media are reshaping health care". Health affairs, 28(2), pp. 361-368.

[10] A. Karami, A.A. Dahl, G. Turner-McGrievy, H. Kharrazi, and G. Shaw. 2018. "Characterizing diabetes, diet, exercise, and obesity comments on Twitter". International Journal of Information Management, 38(1), pp. 1-6.

[11] N. Kordzadeh. Social Media in Health Care, in Contemporary Consumer Health Informatics. 2016, Springer. p. 101-123.

[12] N. Kordzadeh and D.K. Young. 2018. "Exploring Hospitals' Use of Facebook: Thematic Analysis". Journal of Medical Internet Research, 20(5), pp. e190.

[13] n.d. Best Hospitals National Rankings. 2018 [cited 2018; Available from: https://health.usnews.com/besthospitals/rankings.

[14] H. Park, B.H. Reber, and M.-G. Chon. 2016. "Tweeting as health communication: health organizations' use of twitter for health promotion and public engagement". Journal of Health Communication, 21(2), pp. 188-198.

[15] H. Park, S. Rodgers, and J. Stemmle. 2013. "Analyzing health organizations' use of Twitter for promoting health literacy". Journal of Health Communication, 18(4), pp. 410425.

[16] J. So, A. Prestin, L. Lee, Y. Wang, J. Yen, and W.-Y.S. Chou. 2016. "What do people like to "share" about obesity? A content analysis of frequent retweets about obesity on Twitter". Health Communication, 31(2), pp. 193-206.

[17] S.I. Thaker, A.S. Nowacki, N.B. Mehta, and A.R. Edwards. 2011. "How US hospitals use social media". Annals of Internal Medicine, 154(10), pp. 707-708.

[18] L. Thomas and J.M. Woodside. 2016. "Social media maturity model". International Journal of Healthcare Management, 9(1), pp. 67-73. 